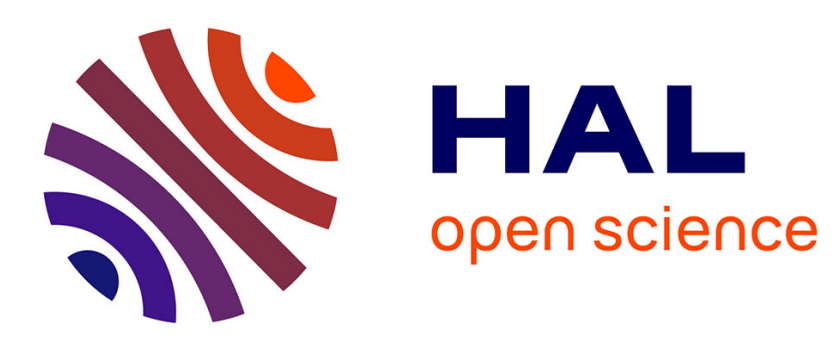

\title{
A Multipurpose Fast Neutron Beam Capability at the MASURCA Facility
}

L. Dioni, R. Jacqmin, M. Sumini, B. Stout

\section{To cite this version:}

L. Dioni, R. Jacqmin, M. Sumini, B. Stout. A Multipurpose Fast Neutron Beam Capability at the MASURCA Facility. ANNIMA 2015 - Advancements in Nuclear Instrumentation Measurement Methods and their Applications, Apr 2015, Lisbonne, Portugal. cea-02491656

\section{HAL Id: cea-02491656 https://hal-cea.archives-ouvertes.fr/cea-02491656}

Submitted on 26 Feb 2020

HAL is a multi-disciplinary open access archive for the deposit and dissemination of scientific research documents, whether they are published or not. The documents may come from teaching and research institutions in France or abroad, or from public or private research centers.
L'archive ouverte pluridisciplinaire HAL, est destinée au dépôt et à la diffusion de documents scientifiques de niveau recherche, publiés ou non, émanant des établissements d'enseignement et de recherche français ou étrangers, des laboratoires publics ou privés. 


\title{
A Multipurpose Fast Neutron Beam Capability at the MASURCA Facility
}

\author{
L. Dioni, R. Jacqmin, M. Sumini, B. Stout
}

\begin{abstract}
In this paper we investigate the possible future use of the CEA Cadarache MASURCA experimental fast reactor to generate a fairly high-intensity continuous beam of fast neutrons, having energies distributed in the $1 \mathrm{KeV}$ to $5 \mathrm{MeV}$ range. Such an extracted beam of fast neutrons, tailorable in intensity, size and energy, would be rather unique; it would be of interest to neutron-based research and could open a range of new applications at MASURCA. We report the results of numerical simulations which have been performed to evaluate the feasibility of such a beam port and to characterize it spectrally.
\end{abstract}

\section{INTRODUCTION}

$\mathrm{M}$ ASURCA, which stands for "mock-up facility for fast breeder reactor studies at Cadarache" is a zero-power critical facility, which was built in the 60's for the purpose of studying experimentally the physics of fast neutron lattices and cores [1].

Until the early 90's, MASURCA was operated almost exclusively for experimental validation studies of sodiumcooled fast neutron reactor cores. Subsequent programs were directed towards nuclear waste transmutation physics, while other similar facilities in Europe and in the USA were permanently shut down. These transmutation experiments, most notably the European Commission sponsored FP5/MUSE-4 program [2] - which involved a sub-critical lead-cooled core coupled with a neutron generator - attracted interest among European countries and were carried out as part of international collaborations.

The MASURCA facility is currently undergoing a major multiyear refurbishment work in preparation for new programs in support of future fast reactors, mainly the ASTRID demonstrator [3]. This work entails not only improvements in the instrumentation and measurement techniques, but also the possible use of the facility for a broader spectrum of fast neutron physics applications.

Manuscript received April 6, 2015. This work was supported by A*MIDEX, initiative d'excellence Aix-Marseille.

Luca Dioni is with the Institut Fresnel, Aix-Marseille Université, 13013 Marseille, France; with the Department of Industrial Engineering, Università di Bologna, 40136 Bologna, Italy; and with the Laboratoire d'Etude de Physique, CEA-DEN/CAD/DER/SPRC/LEPh, 13108 Saint Paul Lez Durance Cedex (e-mail: luca.dioni@ fresnel.fr).

Robert Jacqmin is with the CEA Cadarache, DER/SPRC, 13108 Saint Paul Lez Durance Cedex, France (e-mail: robert.jacqmin @ cea.fr).

Marco Sumini is with the Department of Industrial Engineering, Università di Bologna, 40136 Bologna, Italy.

Brian Stout is with the Institut Fresnel, Aix-Marseille Université, 13013 Marseille, France.
This paper presents the first results of a prospective investigation of MASURCA as a fast neutron source from which a well-characterized fast-neutron "beam" of sufficient intensity could be extracted and used for various purposes. This investigation takes full advantage of the unique features of the facility and of the favourable reactor building characteristics. The feasibility is evaluated by means of modern neutron transport simulation codes, both deterministic and Monte Carlo.

\section{THE MASURCA FACILITY}

\section{A. Main Features}

MASURCA (Fig. 1a) is a low-power, air-cooled reactor having a rated maximum neutron flux level of about $10^{11}$ neutrons $\mathrm{cm}^{-2} \mathrm{~s}^{-1}$ at the core centre, which corresponds to a thermal power of $5 \mathrm{~kW}$ [4].

Experimental configurations are constructed by loading subassemblies (called "tubes"), vertically, in a square lattice. These stainless steel structure tubes have a $106 \mathrm{~mm}$ x $106 \mathrm{~mm}$ horizontal cross section and are about four meter long. They are filled with small rodlets or platelets of various types (fissile, fertile, structure, coolant, absorber, air, etc.), arranged in such a way as to represent average material concentrations and geometrical patterns of interest (Fig. 1b). Hundreds of such tubes can be loaded, allowing core diameters up to approximately $3.8 \mathrm{~m}$. A typical experimental configuration consists of a quasi-cylindrical fissile core, radially surrounded by a fertile blanket or steel reflector, itself surrounded by shielding tubes. As a consequence of the large and diverse inventories of materials available at MASURCA, there is considerable flexibility in the configurations that can be simulated.

A shutdown mechanism is provided by four to eight Safety Rods (SR), depending on the characteristics and size of the core. A calibrated, low-worth Pilot Rod (PR) is used to adjust the core reactivity near the critical state.

Some of the structure tubes have openings in their opposite sides, at mid-height, so that horizontal measurements channels running across the core in the $X$ and $Y$ directions can be made. Local measurements are typically obtained by moving small fission chambers through such radial channels, from the open space surrounding the biological shield (Label 18 in Fig. 1). A radial channel as large as $10 \times 10 \mathrm{~cm}^{2}$ in cross-sectional area 


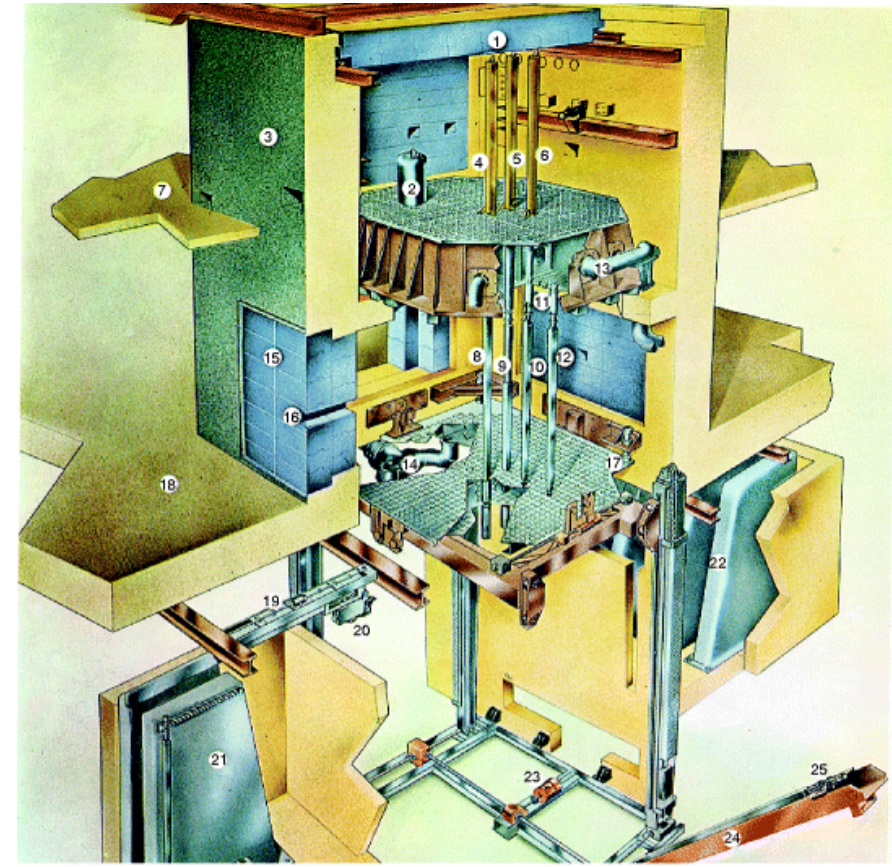

1: Rolling slabs

2: Start-up source

3: Biological shield

4: Type 1 control rod mechanism

5: Type 2 control rod mechanism

6: Pilot rod mechanism

7: Level +4.94 m

8: Type 1 rod

9: Type 2 rod

10: Pilot rod

11: Suspension nozzle

12: Tube

13: Core input ventilation

14: Core output ventilation

15: Removable biological shield

16: Radial channel

17: Centring plate

18: Level +0.00

19: XY East handling arm

20: XY trolley

21: East vertical storage

22: West vertical storage

23: Centring plate mechanism

24: Upending device

25: Tube head

a)

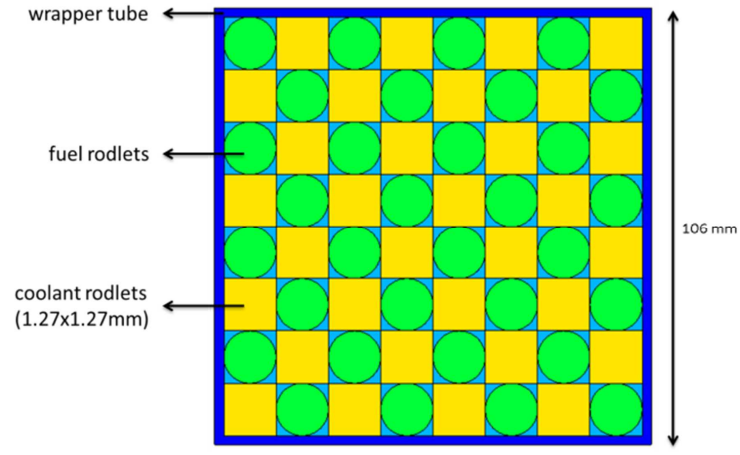

b)

Fig. 1. (a) Cut-away View of the MASURCA Reactor Building and (b) an Example of a Typical MASURCA Fuel Tube Arrangement.

can even be arranged (Label 16 in Fig. 1), as was done for the MUSE-4 experiments, which are further discussed below.

\section{B. The MUSE-4 Program as an illustration of the MASURCA flexibility}

The high flexibility of MASURCA is best exemplified by the MUSE-4 program (2000-2004) [2]. In this series of experiments, a neutron source was generated by fusion reactions of deutons impacting a tritium (or deuterium) target

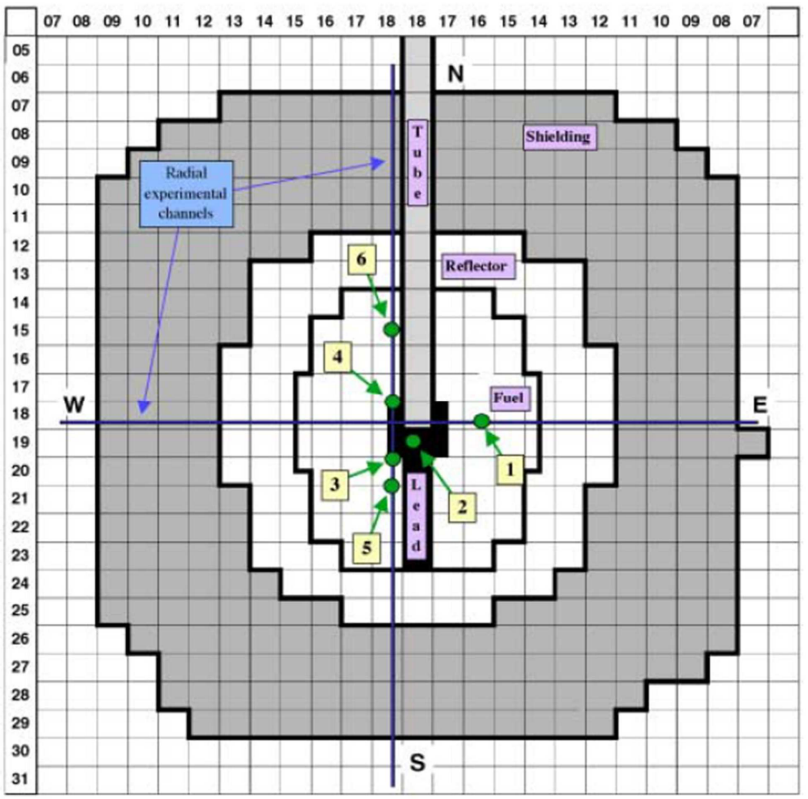

Fig. 2. Horizontal Cross-sectional View of the MUSE-4 Critical Configuration, the Numbers Indicate the Positions of the Foils (for Foil Activation Measurement) in the Experimental Channels [5].

placed at the centre of various sub-critical neutron multiplying media (Fig. 2). This setup was used to investigate the physics of ADSs (Accelerator Driven Systems).

The GENEPI variable-frequency pulsed deuton accelerator and its associated high-voltage $250 \mathrm{kV}$ unit were conveniently located in the large open space provided by the "accelerator room" on the North side of the reactor hall, which was already equipped with a biological shield. The deuton beam was focussed and transported to the MASURCA core centre thru a vacuum guide tube running through a pre-arranged $10 \times 10 \mathrm{~cm}^{2}$ radial channel, from an opening made in the reactor biological shield. Further advantage was taken of the large space available in the accelerator room to install an on-line beam monitoring instrument, facing the opening. This instrument was made of silicon detectors which detected the protons and alpha particles emitted at nearly $180^{\circ}$ angle of the incident beam and returning thru the guide tube.

\section{MOTIVATION FOR AN EXTRACTED NEUTRON BEAM}

The preceding considerations suggest that MASURCA could be used as a versatile fast neutron source capable of delivering a steady fast neutron flux of up to $10^{11}$ neutrons $\mathrm{cm}$ $2 \mathrm{~s}^{-1}$ in all directions, and that a fraction of this neutron flux having energies distributed in the $1 \mathrm{keV}$ to $5 \mathrm{MeV}$ range could be delivered to the accelerator room thru a prearranged radial air (or vacuum) channel and an adjustable-size window in the biological shield. This opportunity results from the combination of several favourable features: fast neutron spectrum, kW-level thermal power as opposed to just $\sim 100 \mathrm{~W}$ in most critical facilities, small neutron attenuation thru air in experimental channels, easy access to the reactor core from all 
sides, large and diverse inventories of materials so that the neutron source spectrum can be tailored to different needs.

Such an extracted "beam" of fast neutrons adaptable in intensity, size and energy spectrum, could serve several purposes. Potential applications include neutron activation analyses, semi-integral neutron cross section measurements, testing of medical equipment for neutron capture therapy, validation of neutron radiography systems for the detection of nuclear materials, neutron instrumentation testing, etc.

Before definite statements can be made about the practical use of such a beam for specific applications, several conditions must be met. These conditions relate to the beam characteristics in intensity, energy spectrum, gamma-toneutron background, at various positions along the channel, as well as to the sensitivity of these characteristics to changes in the source neutrons and in the general experimental setup. These feasibility issues were investigated by numerical simulations, which are described hereafter.

\section{FEASIBILITY STUDY}

\section{A. Calculation models}

For this feasibility study, two 3-D quasi-spherical models of small sodium-cooled fast reactor cores were considered. Such simple models have the advantage of not requiring large computational times, while being sufficiently representative of the main physics phenomena for a preliminary assessment. The two models differ only in the type of fuel utilized: one is a MOX fuel, based on the fissile isotope $\mathrm{Pu}^{239}$ (Configuration $M O X$ ), while the other one is a metallic fuel, based on $\mathrm{U}^{235}$ (Configuration U-METAL). The isotopic fractions are shown in Table I.

TABLE I. Fuel COMPositions OF THE Two MODELS

\begin{tabular}{lllc} 
Configuration & Element & Isotope & Fraction $(\%)$ \\
\hline MOX & $\mathrm{Pu}(\sim 27 \%)$ & $\mathrm{Pu}^{238}$ & 0.2 \\
& & $\mathrm{Pu}^{239}$ & 78.7 \\
& $\mathrm{Pu}^{240}$ & 19.1 \\
& & $\mathrm{Pu}^{241}$ & 1.4 \\
& & $\mathrm{Pu}^{242}$ & 0.7 \\
& $\mathrm{U}(\sim 73 \%)$ & $\mathrm{U}^{235}$ & 0.3 \\
& & $\mathrm{U}^{238}$ & 99.6 \\
& & & \\
& & & \\
& & & \\
& & & \\
& & & \\
& & $\mathrm{U}^{235}$ & 69.3 \\
\hline
\end{tabular}

The fissile core is centred at the $X=0, Y=0$ position in the MASURCA co-ordinate system. It is surrounded by a $32-\mathrm{cm}$ thick reflector composed of sodium and stainless steel (Fig. 3). This reflector shell is itself surrounded radially by a $43-\mathrm{cm}$ shield made of steel and absorber materials. About one meter of air separates the core from a biological shield made of 90 $\mathrm{cm}$ of concrete.

In these simple concentric spherical shell models, the radial beam channel is approximated by a right circular air-filled

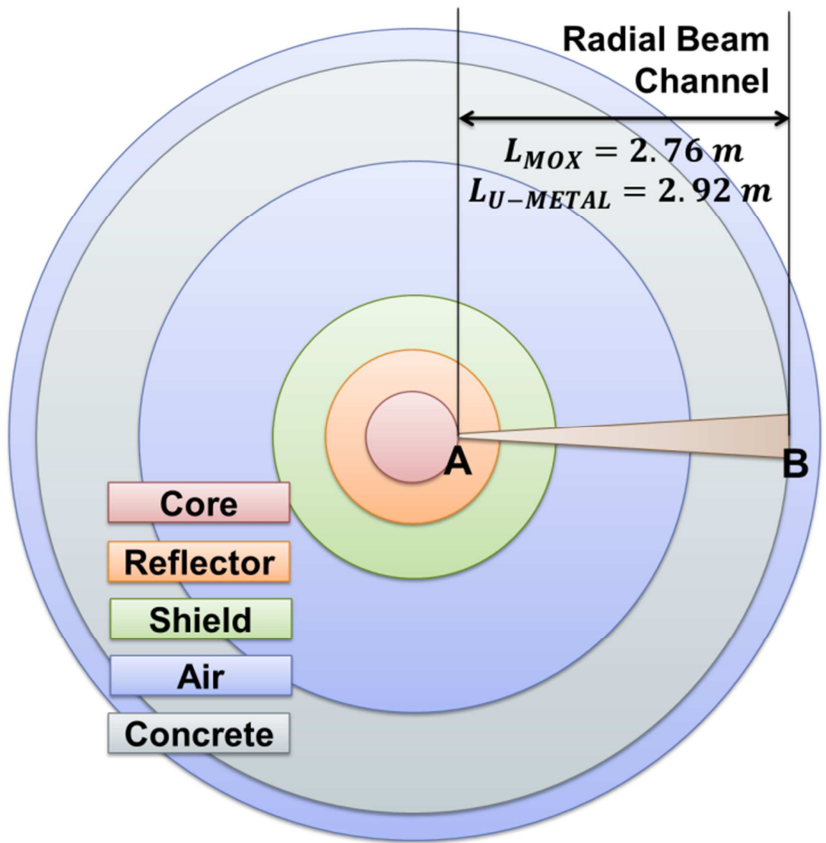

Fig. 3. Schematic View of the Calculation Models.

cone starting at the core-reflector interface (A), having its vertex at the centre of the spheres and extending outwards past the concrete wall (B). The opening angle of the cone was derived from the constraint of a maximum beam exit port radius of $\sim 15 \mathrm{~cm}$ in the biological shield, and was found to be 5.36 degrees.

The different zones and geometrical characteristics of the models are summarized in Table II.

TABLE II. GeOMETRICAL ChaRACTERISTICS OF THE CALCUlation ModelS

\begin{tabular}{lllc} 
Configuration & Zone & Main Materials & R sphere $(\mathrm{m})$ \\
\hline MOX & Core & fuel + sodium & 0.44 \\
& Reflector & steel + sodium & 0.76 \\
& Shield & steel + absorbers & 1.18 \\
& Air & & 2.30 \\
& Concrete & & 3.20 \\
U-METAL & & & \\
& Core & fuel + sodium & 0.28 \\
& Reflector & steel + sodium & 0.60 \\
& Shield & steel + absorbers & 1.02 \\
& Air & & 2.30 \\
& Concrete & & 3.20 \\
\hline
\end{tabular}

\section{B. Calculation tools}

The feasibility study was performed with two well-known neutron transport codes: the deterministic code ERANOS2 [6], and the continuous-energy Monte Carlo code TRIPOLI-4 [7], using the nuclear data library JEFF-3.1.

The codes were used in two successive steps. The ERANOS-2 code was first used for finding thecritical radii of the cores (these spherical critical radii shown in Table II were actually derived from realistic $R-Z$ configurations) using the given material concentrations. These critical radii, together with the total (isotropic) flux level in the cores, and the 


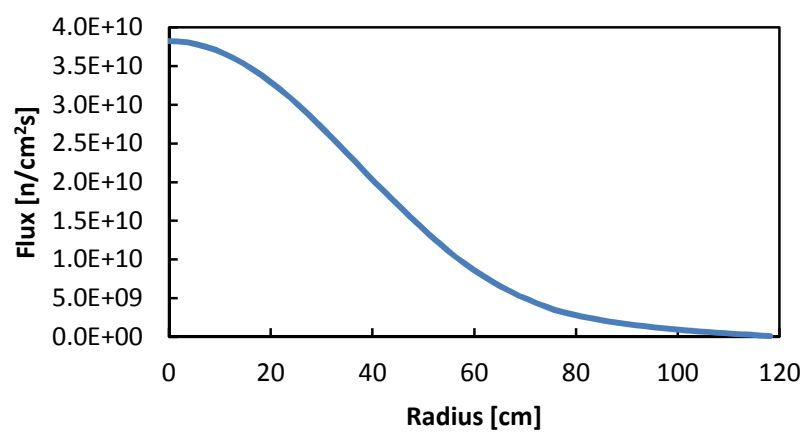

a)

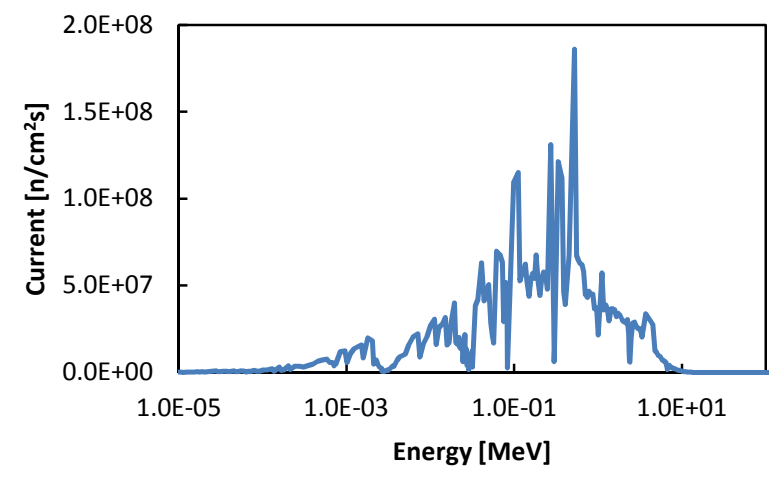

b)

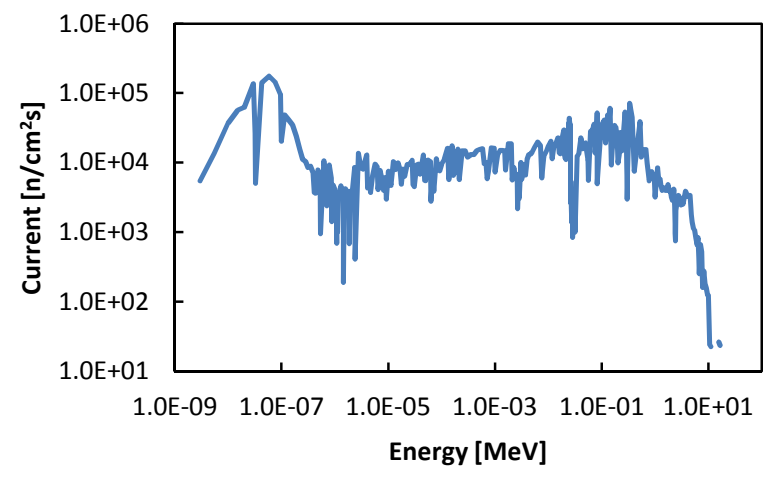

c)

Fig. 4. Configuration MOX: (a) Total Neutron Flux Radial Profile; (b) Energy Spectrum of Neutron Outgoing Current at the Beginning of the Channel; (c) Energy Spectrum of Neutron Outgoing Current at the End of the Channel.

intensities of the fission sources, were then used as inputs to propagation calculations performed with TRIPOLI-4.

In the TRIPOLI-4 simulation, surface tallies were defined to count the particles, both neutrons and photons, travelling in the channel and crossing successive spherical shells within the cone. These tallies provide a measure of the outgoing surface current (particles $\mathrm{cm}^{-2} \mathrm{~s}^{-1}$ ) and energy distribution of the particles. In order to estimate the sensitivity of the neutron spectrum at the exit of the beam (in the biological shield), material changes were made in the core loading and their impact assessed on the "uncollided" portion of the neutron beam, i.e., the fraction of core neutrons in the cone that reach the channel exit port directly from the core edge.

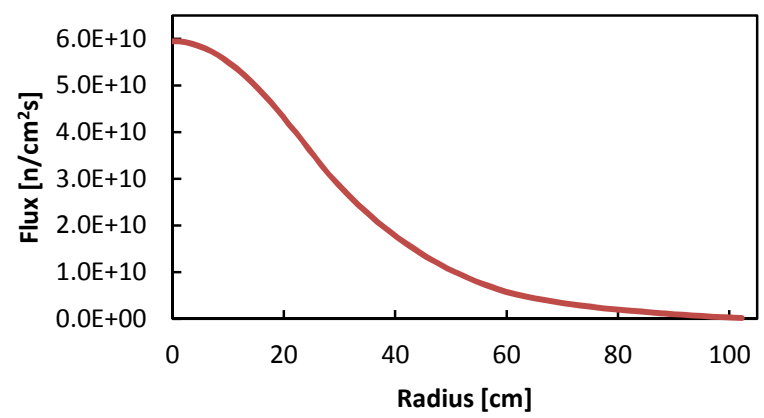

a)

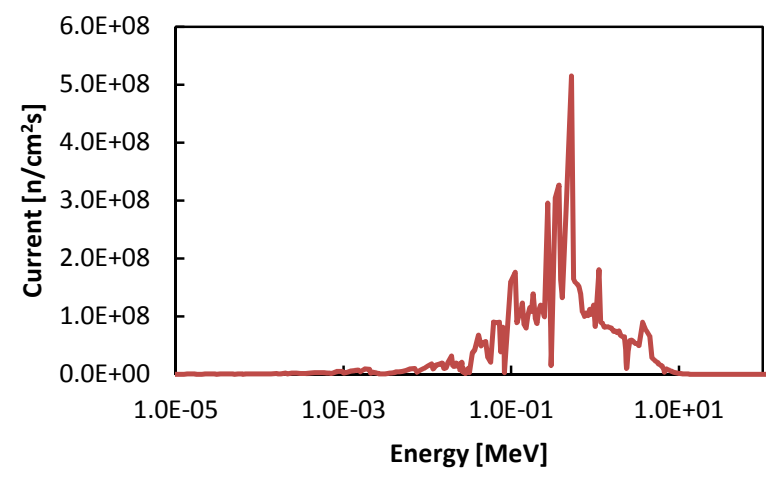

b)

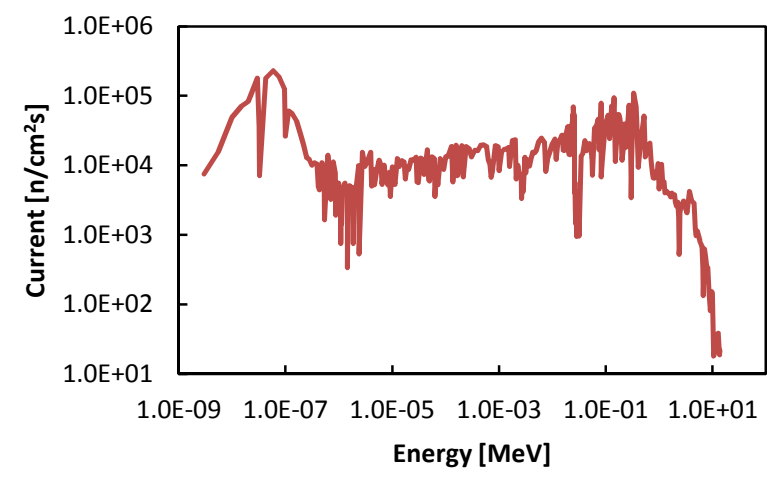

c)

Fig. 5. Configuration U-METAL: (a) Total Neutron Flux Radial Profile; (b) Energy Spectrum of Neutron Outgoing Current at the Beginning of the Channel; (c) Energy Spectrum of Neutron Outgoing Current at the End of the Channel.

A zero current of returning particles was set on the outer shell boundary. All calculations were normalized at $1 \mathrm{~kW}$ total thermal power.

\section{RESULTS AND DISCUSSION}

The radial profile of the total neutron flux is shown in Fig. 4a for Configuration MOX and Fig. 5a for Configuration $U$ $M E T A L$. The (isotropic) neutron flux level at the core centre is on the order of $10^{10}$ neutrons $\mathrm{cm}^{-2} \mathrm{~s}^{-1}$.

In either configuration, the neutron current intensity (directional flux) at the channel entrance is on the order of $10^{9}$ neutrons $\mathrm{cm}^{-2} \mathrm{~s}^{-1}$, and on the order of $10^{6}$ neutrons $\mathrm{cm}^{-2} \mathrm{~s}^{-1}$ at the channel exit. This intensity compares favourably with those of other machines in which attempts have been made to 




$\begin{array}{llllll}1.0 \mathrm{E}-09 & 1.0 \mathrm{E}-07 & 1.0 \mathrm{E}-05 & 1.0 \mathrm{E}-03 & 1.0 \mathrm{E}-01 & 1.0 \mathrm{E}+01\end{array}$

Energy [MeV]

a)

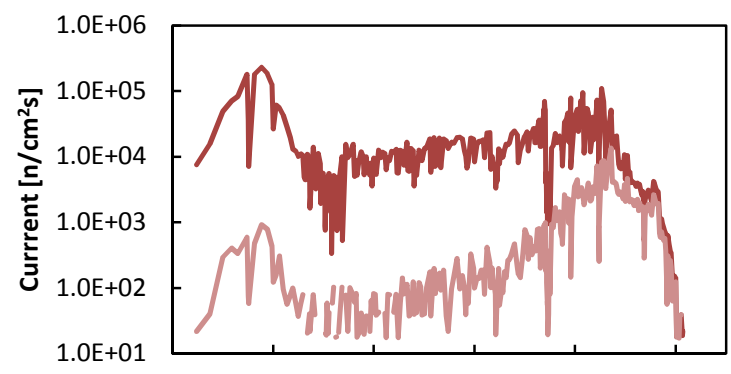

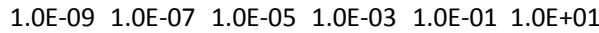

Energy [MeV]

b)

Fig. 6. (a) Comparison Between Total and Uncollided Neutron Current at the End of the Channel for Configuration MOX and (b) for Configuration $U$ $M E T A L$.

develop fast neutron beams. Note that, should that be deemed necessary, higher outgoing beam intensities could be reached by moving the core off-centre, in the direction of the channel, and simultaneously reducing the reflector or shield thickness.

Figs. $4 \mathrm{~b}$ and $4 \mathrm{c}$ show the energy distribution of the outgoing neutron current at the beginning of the channel (A), at the core-reflector interface, and at the end of the channel (B) at the outer boundary, for Configuration MOX. Figs. 5b and 5c show the corresponding plots for Configuration U-METAL.

The total exiting neutron spectrum retains some of the source fast neutron distribution characteristics, but also includes, as expected, a slowing-down component, due to the many scattered neutrons that come from the whole system, as no attempt was made to filter those out in this preliminary investigation.

In order to appreciate the relative importance of the scattered neutrons, the spectra of uncollided neutrons are plotted in Fig. 6. The results are compared with the total spectrum obtained for Configuration MOX (Fig. 6a) and Configuration U-METAL (Fig. 6b).

Fig. 6 provides information about the origin of the neutrons reaching the channel exit. The highest part of the spectrum ( $\mathrm{MeV}$ range) is dominated by neutrons coming directly from the core, while there is a growing contribution of scattered neutrons as one moves to lower energies, especially in the $\mathrm{keV}$ and lower energy regions. It is interesting to note that the detailed energy structure down to $\sim 1 \mathrm{keV}$ (especially around

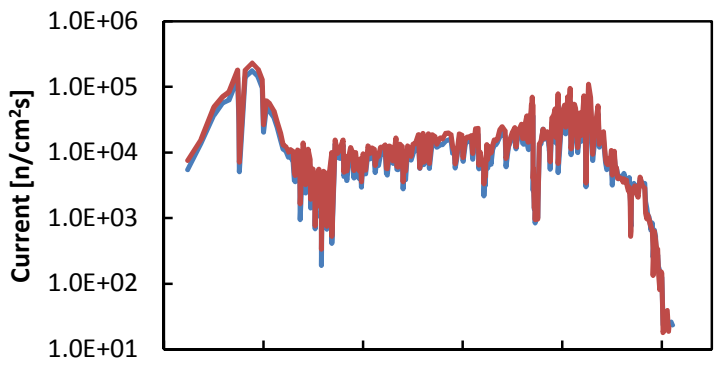

1.00E-091.00E-071.00E-051.00E-031.00E-011.00E+01

Energy [MeV]

a)

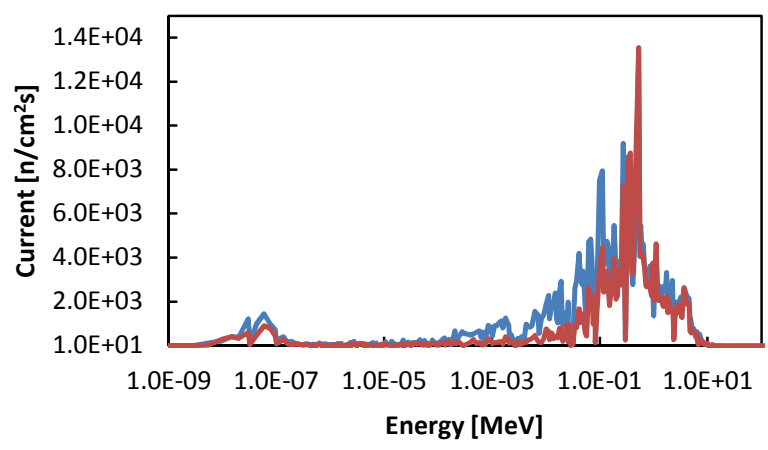

b)

Fig. 7. Computed (a) Total=Collided+Uncollided, and (b) Un-collided Outgoing Current Spectra for Configuration MOX (softer spectrum) and Configuration U-METAL (harder spectrum).

the large $2.8 \mathrm{keV} \mathrm{Na-23}$ and $28 \mathrm{keV}$ Fe-56 scattering resonances) is preserved though.

The intensity of the total uncollided current is on the order of $10^{5}$ neutrons $\mathrm{cm}^{-2} \mathrm{~s}^{-1}$, which is about an order of magnitude lower than the total beam intensity at the channel exit. Regarding the intensity of the outgoing gamma-ray current at the end of the channel, it is on the order of $10^{5}$ photons $\mathrm{cm}^{-2} \mathrm{~s}^{-}$ 1, a relatively high value which will require appropriate shielding and proper discrimination in the detection system.

In Fig. 4b and Fig. 5b, the harder spectrum of the uranium metal system (Configuration U-METAL), compared with the plutonium oxide system (Configuration $M O X$ ), is clearly visible at the beginning of the beam, but much less so at the channel exit (Fig. 7a).

In order to appreciate this difference better, the outgoing current of uncollided neutrons has been plotted in Fig. 7b, at the exit of the channel.

In Table III, the fractions of outgoing neutrons are compared over three energy intervals: thermal $\left(\mathrm{E}_{\mathrm{th}}<0.5 \mathrm{eV}\right)$, epithermal $\left(0.5 \mathrm{eV}<\mathrm{E}_{\text {epi }}<10 \mathrm{KeV}\right)$ and fast $\left(\mathrm{E}_{\text {fast }}>10 \mathrm{KeV}\right)$.

TABLE III. Fractions OF THERMAL, EPITHERMAL AND FAST NEUTRONS IN THE TOTAL AND UNCOLLIDED OUTGOING CURRENTS

\begin{tabular}{lllll} 
& $\mathrm{J}_{\text {total }}$ & $\mathrm{J}_{\text {th }} / \mathrm{J}_{\text {total }}$ & $\mathrm{J}_{\text {epi }} / \mathrm{J}_{\text {total }}$ & $\mathrm{J}_{\text {fast }} / \mathrm{J}_{\text {total }}$ \\
\hline Total $_{M O X}$ & $4.07 \times 10^{6}$ & 0.28 & 0.27 & 0.45 \\
Uncollided $_{\text {MOX }}$ & $3.48 \times 10^{5}$ & 0.02 & 0.10 & 0.88 \\
Total $_{U-M E T A L}$ & $5.23 \times 10^{6}$ & 0.28 & 0.25 & 0.46 \\
Uncollided $_{\text {U-METAL }}$ & $2.63 \times 10^{5}$ & 0.02 & 0.05 & 0.93 \\
\hline
\end{tabular}


It can be concluded from Fig. 7 and Table III that the contribution of scattered neutrons dominates that of the uncollided neutrons at the beam exit by more than an order of magnitude, with the consequence that differences in core fissile constituents are hardly visible. Different geometrical arrangements could have been considered to modify this ratio and achieve a higher proportion of uncollided neutrons, but this possibility was not investigated as part of this initial study.

\section{CONCLUSION}

In this prospective study, we investigated the possible use of the MASURCA experimental reactor as a fast neutron beam source, taking advantage of the unique features and high flexibility of the facility. Simple spherical models were used to quantify the intensity, energy spectrum, and sensitivity of the directional neutron flux, which would travel in a speciallyarranged radial air-filled channel and exit past the biological shield, in the adjacent "accelerator room", some 2.7 to 2.9 meters away from the core outer surface.

Results of numerical simulations show that a neutron current on the order of $\sim 410^{6}$ neutrons $\mathrm{cm}^{-2} \mathrm{~s}^{-1}$ can be reached at the channel exit, when the core is operated at $1 \mathrm{~kW}$ thermal power, corresponding to a central flux of $3.810^{10}$ neutrons $\mathrm{cm}^{-}$ ${ }_{2} \mathrm{~s}^{-1}$. The corresponding gamma flux level at the channel exit was found to be about $10^{5}$ photons $\mathrm{cm}^{-2} \mathrm{~s}^{-1}$. As expected, the spectrum of the exiting neutrons contains a significant intermediate-energy component, resulting in a low sensitivity to the core fissile constituents. Indeed, in the model setups considered, only about 5 to $10 \%$ of the neutrons in the exiting beam are uncollided neutrons from the core, the others being neutrons that have undergone scattering collisions in various parts of the system.

On the basis of these preliminary findings, we conclude that MASURCA definitely has the potential for delivering a continuous fast neutron beam of some $\sim 10^{7}$ neutrons $\mathrm{cm}^{-2} \mathrm{~s}^{-1}$ in the accelerator room, $70 \%$ of those neutrons having energies in the $10 \mathrm{keV}$ to $5 \mathrm{MeV}$ range. Such a fairly high intensity neutron beam could have several applications. Further studies are needed to determine geometrical setups (off-centred core position, filters, ...), in which the relative contribution of uncollided neutrons would be significantly increased, and thereby the sensitivity to the core fissile constituents improved. As part of these studies, fast neutron spectrometric techniques will be investigated, capable of providing a high energy resolution characterization of the beam.

\section{ACKNOWLEDGMENTS}

We thank the Laboratoire d'Etudes de Physique of the CEA Cadarache (CEA-DEN/CAD/DER/SPRC/LEPh), especially Yannick Peneliau and Jean Tommasi, for their technical assistance.
This work has been carried out thanks to the support of the A*MIDEX grant ( ${ }^{\circ}$ ANR-11-IDEX-0001-02) funded by the French Government «Investissementsd'Avenir » program.

\section{REFERENCES}

[1] G. Bignan, et al., "Experimental Reactor Physics Perspectives in France", PHYSOR'08: International Conference on the Physics of Reactors 'Nuclear Power: A Sustainable Resource', Switzerland, 2008.

[2] F. Mellier (Co-ordinator), "The MUSE experiments for sub critical neutronics validation". Final report of the EU-supported project MUSE, Contract No: FIKW-CT-2000-00063, 2005.

[3] Fourth-generation Sodium-cooled Fast Reactors - The ASTRID Technological Demonstrator, Online CEA Report: http://www.cea.fr/content/download/131897/2449556/file/4thgeneration-sodium-cooled-fast-reactors.pdf, December 2012.

[4] W. Assal, J. C. Bosq and F. Mellier, "Experimental Measurements at the MASURCA Facility," IEEE Trans. Nucl. Sci., vol. 59, no. 6, pp. 31803188, Dec. 2012.

[5] J. F. Lebrat, et al., "Global Results from Deterministic and Stochastic Analysis of the MUSE-4 Experiments on the Neutronics of AcceleratorDriven System”, Nuclear Science and Engineering, 158, 49-67, 2008.

[6] G. Rimpault, D. Honde, J. Tommasi, J.M. Rieunier, R. Jacqmin, D. Verrier, D. Biron, "The ERANOS Data and Code System for Fast Reactor Neutronic Analyses," International conference on the New Frontiers of Nuclear Technology: Reactor Physics, Safety and HighPerformance Computing, PHYSOR 2002, Seoul, Korea, October 2-10, 2002.

[7] J.-C. Trama et al, "Overview of TRIPOLI-4 version 7 Continuous Energy Monte Carlo Code," International Congress on Advances in Nuclear Power Plants 2011 (ICAPP 2011), Nice, France, May 2-5, 2011. 